\title{
Sistema Construtivo Quarter Log para Habitação no Espírito Santo: Desenvolvimento do Produto
}

\author{
Emanuella Sossai Altoé1,2, Cristina Engel de Alvarez¹, Gerardo Saelzer² \\ ${ }^{1}$ Laboratório de Planejamento e Projetos - LPP, Departamento de Arquitetura e Urbanismo, \\ Universidade Federal do Espírito Santo - UFES \\ ${ }^{2}$ Universidad del Bio-Bio
}

\begin{abstract}
RESUMO
A habitação tem sofrido transformações devido à necessidade de utilização de critérios construtivos menos impactantes e que garantam o manejo e o uso das edificações alicerçadas em bases conceituais sustentáveis. Assim, surgem novas tecnologias que adotam materiais tradicionais, como a madeira. A pesquisa objetiva desenvolver um sistema construtivo baseado no denominado quarter $\log$ e avaliar o desempenho potencial na etapa de projeto em relação às exigências dos usuários. A metodologia é composta das seguintes etapas: 1 . Caracterização do produto; 2. Identificação das características do Eucalyptus urograndis; 3. Estudo dos condicionantes projetuais para madeira; 4. Definição dos critérios de desempenho; 5. Concepção do sistema/projeto; 6. Avaliação do projeto arquitetônico; e 7. Análise dos dados. Como principal resultado, apresenta-se um sistema construtivo de simples execução que pode ser utilizado pela população residente na região interiorana do Estado, adequando-se às exigências dos usuários para a função de habitação.
\end{abstract}

Palavras-chave: Espírito Santo, quarter log, Eucalyptus urograndis.

\section{"Quarter Log" Construction System for Habitation in the State of Espirito Santo: Product Development}

\begin{abstract}
Habitation has been subjected to transformations, because of the need to use less impacting construction criteria that assure handling and use of buildings based on sustainable concepts. Thus, new technologies that employ traditional materials such as wood have arisen. The purpose of this research was to develop a "quarter log" construction system and assess its potential performance in the design phase regarding users' demands. The methodology comprises the following stages: 1 - Characterization of the product; 2 - Characterization of the Eucalyptus urograndis; 3 - Study of design specificities of the wood; 4 - Definition of performance criteria; 5 - Accomplishment of the project/design; 6 - Design assessment; and 7 - Data analysis. The main results show a construction system of simple execution, which can be used by the population living in countryside region of the State of Espirito Santo, that can suit users' demands on habitation.
\end{abstract}

Keywords: State of Espirito Santo, "quarter log", Eucalyptus urograndis. 


\section{INTRODUÇÃO}

A crise ambiental tem provocado mudanças que envolvem a ciência e a tecnologia, alcançando, inclusive, os processos projetuais e construtivos. Nesse sentido, a criteriosa seleção de materiais contribui para a elaboração de um projeto menos impactante para o meio ambiente, ao considerar inúmeros aspectos cuja avaliação deve envolver desde a extração das respectivas matérias-primas, os processos de beneficiamento e transporte, até o uso e destino final, dando prioridade tanto para os fatores ambientais, quanto para os aspectos que visam ao desenvolvimento da sociedade e da economia (Dreyer et al., 2006).

Dentre esses materiais, a madeira é o de maior destaque, principalmente por sua capacidade de rápida renovação na natureza, sendo, portanto, um material considerado de grande importância no desenvolvimento de novos sistemas construtivos, devido às suas características tecnológicas favoráveis à construção civil (Universidad del Bio Bio, 1998). A utilização da madeira nesse setor nem sempre foi realizada de forma correta, considerando os padrões atuais de avaliação, acarretando processos com grande desperdício e, eventualmente, contribuindo para a destruição de matas nativas.

Destaca-se que, devido às condições climáticas, o Brasil é recordista em produtividade de madeira de reflorestamento, sendo o eucalipto o gênero principal. Nesse contexto e de acordo com a Associação Brasileira de Produtores de Florestas Plantadas, o Espírito Santo encontra-se entre os principais Estados produtores do País e, considerando a proporcionalidade da área territorial em relação aos demais, pode-se afirmar que essa produção é bastante elevada (ABRAF, 2010; Santos \& Aguilar, 2007).

Cabe ressaltar que o principal destino desse cultivo é a produção de celulose e carvão, no entanto, questiona-se atualmente sobre a possibilidade de incremento para usos com maior valor agregado e, dentre eles, a construção civil, cujo potencial é perceptível para as diversas espécies de eucalipto cultivadas até o momento. Nesse sentido, esta pesquisa objetiva o desenvolvimento de um sistema construtivo - especificamente o subsistema vedação vertical -, caracterizado pela fácil execução e pelo atendimento às exigências dos usuários, prevendo-se a utilização do Eucalyptus urograndis na construção civil habitacional. Prevê-se que os principais usuários serão moradores das regiões interioranas do Espírito Santo, cuja familiaridade com a madeira em contraposição à carência de infraestrutura tecnológica para a produção em série são elementos fundamentais para a proposição do sistema. Destacase, ainda, que o sistema quarter log teve sua base conceitual estabelecida a partir de Rocha (1994).

\section{MATERIAL E MÉTODOS}

A metodologia utilizada foi composta pelas seguintes etapas, a seguir detalhadas: 1 . Caracterização do produto a ser desenvolvido (vedação vertical); 2. Identificação das características específicas do Eucalyptus urograndis em relação ao uso pretendido; 3. Estudo dos condicionantes projetuais para uma edificação em madeira; 4. Definição dos critérios para a análise de desempenho; 5. Concepção do sistema/projeto; 6. Avaliação do projeto arquitetônico; e 7. Análise dos dados.

\subsection{Etapa 1: caracterização do produto a ser desenvolvido (vedação vertical)}

Segundo Elder (1977), o subsistema vedação vertical juntamente com as esquadrias e os revestimentos são empregados para oferecer condições de habitabilidade aos usuários e, dentre suas várias funções, destaca-se a de definir limites entre o meio externo e interno do edifício e de atuar estruturalmente e esteticamente. Sabbatini \& Franco (2001) classificam as vedações verticais de acordo com:

- Disposição no edifício: vedação interna/vedação externa;

- Técnica de execução: conformação - moldagem a úmido no local/acoplamento a seco - montagem através de fixação (pregos, parafusos, etc.)/ acoplamento úmido - montagem a seco de componentes com solidarização posterior com argamassa ou concreto;

- Densidade superficial: leve - vedação de baixa densidade superficial, de 60 a $100 \mathrm{~kg} / \mathrm{m}^{2}$; pesada - densidade superior ao 
limite convencionado, e pode ou não ter função estrutural;

- Estruturação: autoportante/estruturada - possui estrutura reticulada para suportar os componentes de vedação;

- Continuidade do plano: contínua - a absorção dos esforços ocorre no plano como um todo; descontínua - a absorção é distribuída para a estrutura; e

- Visibilidade das juntas: monolítica - sem juntas aparentes; modular - com juntas aparentes.

A vedação vertical quando executado em madeira, pode ser classificada, ainda, de acordo com o grau de industrialização empregado (JUNAC, 1984), ou seja: 1. Sistema não industrializado (sistema vernacular; sistema habilitado ou semi pré-cortado); 2. Sistema semi-industrializado (sistema pré-cortado); e 3. Sistema industrializado (pré-fabricação parcial: componentes pré-cortados e painéis pré-fabricados; e pré-fabricação total: módulos pré- fabricados). Diante do apresentado, o objeto de estudo desta pesquisa é classificado como: vedação externa, com execução por acoplamento a seco, leve, estruturada, descontínua, modular - quanto à visibilidade das juntas -, e semi-industrializada em relação ao processo de fabricação.

\subsection{Etapa 2: identificação das características específicas do Eucalyptus urograndis em relação ao uso pretendido}

De acordo com Calil Júnior \& Brito (2010), o processo de caracterização de uma espécie de madeira corresponde a sua classificação estrutural, através da avaliação laboratorial de cada peça, procedimento considerado inviável. Portanto, este estudo foi realizado com base em pesquisas já efetuadas sobre o Eucalyptus urograndis, especificamente Gonçalves (2006), que caracteriza o material através de amostras coletadas no sul do Estado da Bahia, região que possui peculiaridades ambientais semelhantes às do Espírito Santo, com cultivo de 70 e 166 meses (Tabela 1). Cabe ressaltar que, segundo a Norma Brasileira NBR 7190:1997 (ABNT, 1997), as características a serem consideradas no processo são: a densidade - básica e aparente; a resistência - à compressão paralela às fibras, à tração paralela às fibras e, ao cisalhamento paralelo às fibras; a rigidez - o módulo de elasticidade na compressão paralela às fibras e a compressão normal às fibras; $\mathrm{e}$ a umidade.

Segundo Foelkel (1978), as espécies caracterizadas pela densidade entre 0,45 e $0,65 \mathrm{~g} / \mathrm{cm}^{3}$ são recomendadas para a produção de celulose. Todavia, deve-se considerar o aumento da densidade básica em função da idade da árvore, a qual alcança níveis de crescimento entre 10 e $16 \%$, e a ponderação de Alzate (2004) de que esses valores não restringem as aplicações da madeira, desde que sejam utilizadas técnicas que mitiguem o dano causado por essa característica. Em relação à umidade, é importante citar a sua influência nas propriedades dos materiais, visto que seu aumento ocasiona a redução da resistência do produto. De acordo com a NBR 7190:1997 (ABNT, 1997), o projeto deve ser feito admitindo-se uma das classes de umidade especificadas, as quais têm por finalidade ajustar as propriedades de resistência e de rigidez da madeira em função das condições ambientais nas quais permanecerão as estruturas.

Tabela 1. Característica do Eucalyptus. urograndis. Fonte: Gonçalves (2006).

Table 1. Characteristic of Eucalyptus urograndis. Source: Gonçalves (2006).

\begin{tabular}{|c|c|}
\hline Característica & $\begin{array}{l}\text { Eucalyptus urograndis } \\
\text { teor de umidade: } 12 \%\end{array}$ \\
\hline $\begin{array}{l}\text { Densidade: Influencia a trabalhabilidade, durabilidade natural e } \\
\text { impregnabilidade do material (Gérard et al., 1995) }\end{array}$ & $0,51 \mathrm{~g} / \mathrm{cm}^{3}$, classificado como densidade média \\
\hline $\begin{array}{l}\text { Resistência: aptidão em suportar tensões, determinada pela } \\
\text { análise do módulo de ruptura e de deformação } \\
\text { (Calil Júnior \& Brito, 2010) }\end{array}$ & $\begin{array}{l}120,89 \mathrm{kgf} / \mathrm{cm}^{2} \text {, aos } 70 \text { meses e } 242,94 \mathrm{kgf} / \mathrm{cm}^{2} \\
\text { aos } 166 \mathrm{meses}\end{array}$ \\
\hline $\begin{array}{l}\text { Rigidez: valor médio do módulo de elasticidade, determinado } \\
\text { na fase de comportamento elástico-linear, característica que } \\
\text { determina a habilidade de carregamento das peças estruturais } \\
\text { (Gonçalves, 2006) }\end{array}$ & $\begin{array}{l}14076,41 \mathrm{kgf} / \mathrm{cm}^{2} \text {, aos } 70 \text { meses e } 24957,83 \mathrm{kgf} / \mathrm{cm}^{2} \text {, } \\
\text { aos } 166 \text { meses }\end{array}$ \\
\hline
\end{tabular}


Considerando que, dentre os possíveis defeitos da madeira, a presença de nós e frestas interferem na sua qualidade - provocando a perda local de seção e a redução de resistência - é necessário que esses sejam avaliados de acordo com os critérios determinados pela norma de classificação visual vigente, NBR 8456:1984 (ABNT, 1984) (Esteban, 2010). É importante citar que o aparecimento das frestas e das rachaduras de topo, está diretamente relacionado às tensões de crescimento, entendendose que tais tensões resultam da ação de forças internas que atuam sobre os tecidos das árvores, na busca por mantê-las íntegras e eretas, sendo que todos os tipos de eucalipto apresentam altas taxas de crescimento. No entanto, os danos podem ser mitigados a partir da adoção de técnicas adequadas de manuseio, corte e estocagem das peças.

\subsection{Etapa 3: estudo dos condicionantes projetuais para uma edificação em madeira}

Partindo do pressuposto de que os componentes de uma construção em madeira podem estar expostos a diferentes classes de biodeterioração em função dos organismos xilófagos presentes no local e das condições ambientais que possam favorecer o ataque, o desenvolvimento do projeto deve assegurar uma durabilidade mínima compatível com a sua finalidade. Assim, considerando como indesejável a adoção de métodos de tratamento da madeira contra fungos e insetos não disponíveis na região ou que ocasionem impactos ambientais e/ou risco à saúde dos usuários, adotou-se como premissa fundamental de projeto a possibilidade de substituição de peças danificadas. As questões relacionadas à adoção de seções usuais e de fácil aquisição também foram consideradas, especialmente em função do conceito adotado de aproveitamento dos recursos naturais disponíveis na região. Nesse sentido, o sistema deve, ainda, prever as dificuldades de remoção e transporte das peças, o espaço útil disponível para o trabalho e a compatibilização em relação à durabilidade entre os diferentes materiais utilizados. Sendo a umidade um dos principais fatores de influência nos processos de degradação da madeira, a facilidade de escoamento das águas de chuvas e o desenvolvimento de encaixes que impeçam o acúmulo de umidade são fatores fundamentais para a ampliação da vida útil da edificação (NBR 7190:1997 (ABNT, 1997); Szücs (1992)).

Além dos aspectos referentes às características da matéria-prima, também interfere na concepção do sistema o perfil da mão de obra empregada; a infraestrutura produtiva local; os fatores climáticos; e o local de implantação da edificação (NFPA, 1980).

\subsection{Etapa 4: definição dos critérios para a análise de desempenho}

Desempenho é a propriedade que caracteriza quantitativamente o comportamento de um produto em utilização. A metodologia utilizada para aplicação do conceito de desempenho, de acordo com Mitidieri (1998), consiste na definição das exigências dos usuários, identificação das condições de exposição do edifício, definição dos requisitos e critérios de desempenho, e definição dos métodos de avaliação. Segundo a ABNT, as normas que estabelecem as exigências em relação ao desempenho de uma edificação são a ISO 6241:1984 (ISO, 1984) e a NBR 15575:2010 (ABNT, 2010). Depois da análise dos documentos referenciais, é possível perceber que as exigências estabelecidas pelas duas normas, em linhas gerais, são as mesmas, ou seja: segurança estrutural; segurança contra o fogo; segurança no uso e na operação; estanqueidade; desempenho térmico; desempenho acústico; desempenho lumínico; saúde, higiene e qualidade do ar; funcionalidade e acessibilidade; conforto tátil e antropodinâmico; durabilidade; manutenibilidade; e impacto ambiental.

Nesse sentido, a pesquisa em questão atenderá, designadamente, a NBR 15575:2010 (ABNT, 2010), visto que esta estabelece os requisitos e critérios de desempenho específicos para edifícios habitacionais de até cinco pavimentos e pode ser utilizada na avaliação de desempenho de sistemas construtivos, sendo adequada enquanto instrumento de avaliação do objeto de estudo -, a vedação vertical para residências. Cabe ressaltar que os requisitos gerais descritos pela NBR 15575:2010 (ABNT, 2010) são complementados pelos dados delineados nas NBR 15575-2 a NBR 15575-6, sendo a NBR 15575-4 apontada para a vedação vertical externa, a qual descreve os métodos de avaliação para os critérios (Tabela 2). 
Considerando que a etapa de avaliação referese ao projeto do subsistema construtivo vedação vertical, dentre os dados apresentados na Tabela 2, são passíveis de análise os seguintes critérios: segurança no uso e na operação; estanqueidade; durabilidade e manutenibilidade; funcionalidade; e conforto tátil (descritos na Tabela 4). Cabe ressaltar que os itens segurança contra incêndio, desempenho térmico, desempenho acústico, desempenho lumínico e conforto ambiental, devem ser estimados de acordo com o projeto arquitetônico da edificação.

\subsection{Etapa 5: concepção do sistema/projeto}

A elaboração do projeto foi realizada de acordo com as diretrizes pré-estabelecidas a partir de uma revisão bibliográfica, especialmente no que concerne aos critérios de desempenho, agregando-se, ainda, os seguintes aspectos: facilidade de execução; redução na interferência da forma original da peça; manutenção do caráter rústico no produto final; flexibilidade para o projeto arquitetônico; facilidade de manutenção e limpeza; entre outros.

O sistema construtivo proposto tem sua configuração básica desenvolvida a partir de toras de madeira divididas longitudinalmente em quatro partes iguais, após a retirada das costaneiras, semelhante ao adotado por Rocha (1994) e demonstrado na Figura 1.

A vedação vertical é composta pela junção das partes quarter log, individualmente e independente da estrutura (pilar e viga), visando facilitar sua substituição, caso necessário. A união das peças é realizada por parafusos galvanizados e vergalhões ( $(1 / 2 ")$, os quais permitem o ajuste da vedação conforme a variação dimensional das partes, provocada pela perda de umidade (Figura 2). Cabe ressaltar que o sistema permite uma flexibilidade dimensional cujo limite será dado de acordo com a capacidade infraestrutural do local de implantação, ou seja, locais com disponibilidade

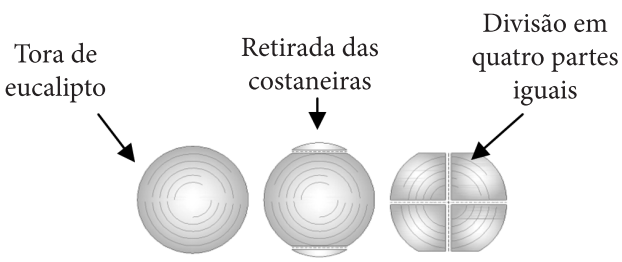

Figura 1. Preparação da peça denominada quarter log. Figure 1. Preparation of the part called quarter log.

Tabela 2. Critérios e métodos de avaliação de desempenho. Fonte: NBR 15575:2010 (ABNT, 2010).

Table 2. Criteria and methods of performance evaluation. Source: NBR 15575:2010 (ABNT, 2010).

\begin{tabular}{|c|c|c|c|}
\hline Critério & Método de avaliação & Critério & Método de avaliação \\
\hline Segurança estrutural & Ensaio laboratorial & Desempenho lumínico & $\begin{array}{l}\text { Análise do projeto ar- } \\
\text { quitetônico da edificação e/ } \\
\text { ou inspeção em protótipo }\end{array}$ \\
\hline Segurança contra incêndio & $\begin{array}{l}\text { Análise do projeto ar- } \\
\text { quitetônico da edificação e/ } \\
\text { ou inspeção em protótipo }\end{array}$ & $\begin{array}{l}\text { Durabilidade e manutenibi- } \\
\text { lidade }\end{array}$ & $\begin{array}{l}\text { Análise do projeto ar- } \\
\text { quitetônico da edificação e } \\
\text { do sistema construtivo }\end{array}$ \\
\hline $\begin{array}{l}\text { Segurança no uso e na } \\
\text { operação }\end{array}$ & $\begin{array}{l}\text { Análise do projeto ar- } \\
\text { quitetônico da edificação e } \\
\text { do sistema construtivo, e/ou } \\
\text { inspeção em protótipo }\end{array}$ & Saúde & Ensaios laboratoriais \\
\hline Estanqueidade & $\begin{array}{c}\text { Ensaio tipo e/ou análise } \\
\text { do projeto arquitetônico } \\
\text { da edificação e do sistema } \\
\text { construtivo }\end{array}$ & Funcionalidade & $\begin{array}{l}\text { Análise do projeto ar- } \\
\text { quitetônico da edificação e } \\
\text { do sistema construtivo }\end{array}$ \\
\hline Desempenho térmico & $\begin{array}{l}\text { Cálculo e análise de projeto } \\
\text { arquitetônico da edificação }\end{array}$ & $\begin{array}{l}\text { Conforto tátil e antropo- } \\
\text { dinâmico }\end{array}$ & $\begin{array}{c}\text { Análise do projeto ar- } \\
\text { quitetônico da edificação e } \\
\text { do sistema construtivo e/ou } \\
\text { ensaios laboratoriais }\end{array}$ \\
\hline Desempenho acústico & $\begin{array}{l}\text { Medições realizadas em } \\
\text { laboratório e em campo }\end{array}$ & Adequação ambiental & $\begin{array}{l}\text { Análise do projeto ar- } \\
\text { quitetônico da edificação }\end{array}$ \\
\hline
\end{tabular}


de equipamentos auxiliares de carga, possibilitam peças maiores e mais pesadas, enquanto locais que dependem essencialmente da força humana oriunda do trabalho braçal, devem ser reduzidos. Outro fator de interferência no dimensionamento das peças são as aberturas oriundas das esquadrias sugerindo-se, assim, que o dimensionamento final seja dado de acordo com as características do projeto arquitetônico e as condições da logística local.

É importante citar que o desenvolvimento do produto respeitou as características do material disponível - idade máxima de 7 anos e diâmetro médio de $0,20 \mathrm{~m}$ - visto que o cultivo do Eucalyptus urograndis no norte do Espírito Santo é recente, especificamente no município de Jaguaré, onde se concentra a pesquisa.

De acordo com a Figura 2, é possível perceber a presença de um vazio entre os pilares após a fixação das peças quarter log. O objetivo deste é abrigar as instalações elétricas e, eventualmente, contribuir em relação ao conforto térmico da edificação, visto que pode ser coberto por um painel e, consequentemente, criar um bolsão de ar. Para evitar o acúmulo de água, sugere-se: que o sistema seja instalado sobre uma base de concreto ou outro material resistente à ação da umidade, com altura aproximada de 0,20 m em relação ao piso; que as instalações hidráulicas sejam realizadas em paredes de alvenaria; e que a cobertura possua beiral com medida suficiente para proteger a madeira da água de chuva.

\subsection{Etapa 6: avaliação do projeto \\ arquitetônico; e etapa 7: análise dos dados}

Os procedimentos de avaliação e a análise dos resultados seguem detalhados no item Resultados e Discussão, a seguir apresentado.

\section{RESULTADOS E DISCUSSÃO}

Para a avaliação do sistema, foi realizado um ensaio projetual e elaborado um roteiro síntese dos aspectos e condicionantes levantados anteriores, e passíveis de análise na fase de projeto (Tabela 3 e 4). Adotou-se como critério de análise a identificação do atendimento ao condicionante e, quando pertinente, o detalhamento do aspecto avaliado.

Os resultados obtidos permitem afirmar que o sistema atende aos critérios identificados na revisão bibliográfica. De acordo com o Tabela 5, é possível perceber que, ao ser comparado ao sistema usual $\log$ home (tora inteira), o quarter log apresenta alguns aspectos diferenciais e positivos que podem ser classificados como um avanço em relação ao sistema tradicional.

As Figuras 3 e 4 ilustram o percurso das águas pluviais em cada sistema em relação à estanqueidade.

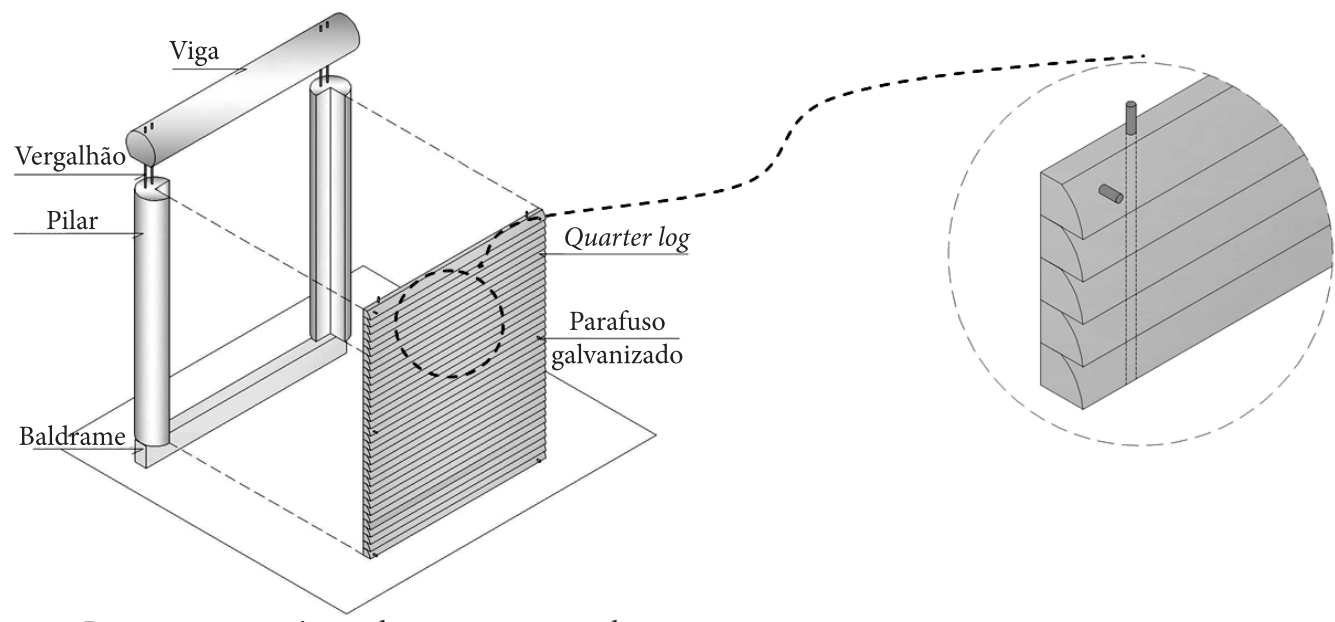

Figura 2. Perspectiva isométrica do sistema quarter log. Figure 2. Isometric view of the system quarter log. 
Tabela 3. Síntese da avaliação em relação aos condicionantes projetuais e à facilidade de execução.

Table 3. Synthesis of evaluation relative to design specificities of the wood and the easy of execution.

\begin{tabular}{|c|c|c|c|}
\hline \multirow{2}{*}{ Item de avaliação } & \multicolumn{2}{|c|}{ Atendimento } & \multirow{2}{*}{ Observações/características projetuais } \\
\hline & Sim & Não & \\
\hline \multicolumn{4}{|l|}{ Condicionantes projetuais } \\
\hline $\begin{array}{l}\text { Proteção das peças de madeira em } \\
\text { relação ao acúmulo de água }\end{array}$ & $\bullet$ & & $\begin{array}{l}\text { - Afastamento entre as peças de madeira e o piso, } \\
\text { através da cinta de baldrame impermeabilizada, } \\
\text { impedindo a umidade ascendente. } \\
\text { - O formato das peças quarter log, cumprem a fun- } \\
\text { ção de pingadeiras e, consequentemente, facilitam o } \\
\text { escoamento da água. }\end{array}$ \\
\hline $\begin{array}{l}\text { Especificação de peças de madeira em } \\
\text { áreas úmidas, como cozinha e banheiro }\end{array}$ & & $\bullet$ & - Utilização de alvenaria nos ambientes úmidos. \\
\hline $\begin{array}{c}\text { Disposição das peças visando eventual } \\
\text { substituição }\end{array}$ & $\bullet$ & & $\begin{array}{l}\text { - O processo de montagem da vedação permite a } \\
\text { substituição de peças deterioradas. }\end{array}$ \\
\hline \multicolumn{4}{|l|}{ Facilidade de execução } \\
\hline $\begin{array}{c}\text { Adoção de seções usuais e de fácil } \\
\text { aquisição }\end{array}$ & $\bullet$ & & $\begin{array}{l}\text { - O sistema é projetado de acordo com a dimensão } \\
\text { das peças disponíveis na região, aproximadamente } \\
0,20 \mathrm{~m} \text {. }\end{array}$ \\
\hline $\begin{array}{l}\text { Reduzida alteração da forma original } \\
\text { das peças de madeira }\end{array}$ & - & & $\begin{array}{l}\text { - A mínima interferência no formato natural das } \\
\text { peças, facilita a utilização em regiões caracterizadas }\end{array}$ \\
\hline $\begin{array}{l}\text { Reduzida tecnologia para a preparação } \\
\text { das peças de madeira }\end{array}$ & $\bullet$ & & $\begin{array}{l}\text { pelo restrito acesso a ferramentas e mão de obra. } \\
\text { Ferramental necessário: plaina desempenadeira } \\
\text { para o desbaste lateral; serra circular para o des- } \\
\text { dobro; máquina destopadeira para o destopo das } \\
\text { peças; e máquina furadeira para a instalação dos } \\
\text { parafusos. }\end{array}$ \\
\hline
\end{tabular}

Tabela 4. Síntese da avaliação em relação aos critérios de desempenho.

Table 4. Synthesis of evaluation relative to performance criteria.

\begin{tabular}{lll} 
Item de avaliação & \multicolumn{2}{c}{ Atendimento } \\
\cline { 2 - 3 } Sim Não & Observações
\end{tabular}

\section{Critérios de desempenho}

\section{Segurança no uso e na operação}

Estanqueidade

Durabilidade e
manutenibilidade
Funcionalidade e
flexibilidade
Conforto tátil

- Não há indícios de prováveis elementos cortantes ou perfurantes que possam causar danos aos usuários.

- A junção das peças através do corte formado pelas retiradas das costaneiras associado à pressão exercida pelo vergalhão possibilitam a estanqueidade do encaixe.

- O formato das peças quarter log facilitam o escoamento da água, conformando pingadeiras.

- Internamente o painel resulta em uma superfície lisa, facilitando o processo de manutenção e higienização da habitação.

- O modo de montagem do sistema objetiva facilitar a substituição das peças de madeira, assim como das barras rosqueadas e dos parafusos galvanizados, caso seja necessário.

- O projeto do sistema permite o acoplamento de portas, resistindo à ação de fechamentos bruscos e a impactos.

- O sistema, por seu potencial de variação métrica, permite a desejável flexibilidade para o projeto arquitetônico.

O sistema não prejudica as atividades normais dos usuários, como caminhar, apoiar e limpar. 
Tabela 5. Comparativo entre o sistema tradicional log home e o sistema proposto quarter log.

Table 5. Comparison between the traditional system log home and the system proposed quarter log.

\begin{tabular}{|c|c|c|}
\hline Requisitos & Sistema tradicional log home & Sistema quarter log \\
\hline Estanqueidade & $\begin{array}{l}\text { - O formato das peças facilita o acu- } \\
\text { mulo de água entre elas (figura 3). }\end{array}$ & $\begin{array}{l}\text { - As peças em quarter log conformam } \\
\text { pingadeiras naturais, auxiliando o } \\
\text { escoamento da água (figura } 4 \text { ). }\end{array}$ \\
\hline $\begin{array}{l}\text { Utilização de materiais de } \\
\text { fontes renováveis }\end{array}$ & $\begin{array}{l}\text { - Grande número de ligações metáli- } \\
\text { cas. }\end{array}$ & $\begin{array}{l}\text { - Menor número de complementos } \\
\text { industrializados. } \\
\text { - Elementos metálicos protegidos pela } \\
\text { própria madeira (barras rosqueadas). }\end{array}$ \\
\hline Consumo energético & $\begin{array}{l}\text { - Peças de madeira produzidas através } \\
\text { de sistemas industrializados com } \\
\text { maior número de etapas e tempo no } \\
\text { processamento. }\end{array}$ & $\begin{array}{l}\text { - Peças de madeira simplificadas com } \\
\text { menor número de etapas e tempo } \\
\text { reduzido para o processamento das } \\
\text { peças. }\end{array}$ \\
\hline $\begin{array}{l}\text { Facilidade de produção } \\
\text { e montagem }\end{array}$ & $\begin{array}{l}\text { - Máquinas e ferramentas industriais. } \\
\text { - Mão de obra especializada. }\end{array}$ & $\begin{array}{l}\text { - Máquinas e ferramentas disponíveis } \\
\text { na região. } \\
\text { - Mão de obra com noções básicas de } \\
\text { carpintaria. }\end{array}$ \\
\hline Custo & $\begin{array}{l}\text { - Maior volume de madeira na en- } \\
\text { voltória. } \\
\text { - Necessidade de transporte da } \\
\text { matéria-prima para a fábrica e desta } \\
\text { para o canteiro de obras }\end{array}$ & $\begin{array}{l}\text { - Menor volume de madeira na } \\
\text { envoltória. } \\
\text { - Matéria-prima obtida nas prox- } \\
\text { imidades do canteiro, reduzindo a } \\
\text { necessidade de transporte de material } \\
\text { e mão de obra. }\end{array}$ \\
\hline
\end{tabular}

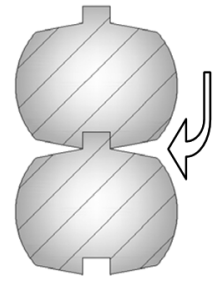

Figura 3. Sistema tradicional log home.

Figure 3. System traditional log home.

\section{CONCLUSÕES}

Embora a utilização da madeira na construção civil no Brasil ainda enfrente obstáculos, sejam técnicos ou culturais, o desenvolvimento de pesquisas e a disseminação de informações sobre as qualidades do material podem colaborar para o avanço no setor, seja em relação ao conhecimento específico, seja na ruptura de paradigmas estabelecidos ao longo do tempo. Observa-se que a construção de unidades habitacionais em madeira não pode, ainda, ser vista como uma solução de baixo custo para casas populares em qualquer local do País, porém, a população que lida com o material (madeira), ou que convive com as grandes áreas de plantio de

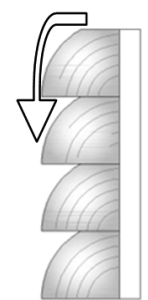

Figura 4. Sistema quarter log. Figure 4. System quarter log.

eucalipto ou similar, tem plenas condições - técnicas e culturais - para assimilar os aspectos inerentes a uma edificação em madeira e, eventualmente, auxiliar no processo construtivo. Para que isso aconteça, torna-se necessário o desenvolvimento de um sistema adequado à realidade dessa população e às características da matéria-prima disponível na região, sendo esse o objetivo principal desta pesquisa.

Nesta etapa de avaliação projetual do quarter log, a análise permitiu identificar que outros itens necessitam maior aperfeiçoamento, como por exemplo, o detalhamento da união entre os componentes do sistema e as esquadrias - janelas e portas - disponíveis no mercado. Assim, as próximas etapas a serem cumpridas para a finalização do 
produto são: detalhamento do projeto; construção de protótipo; avaliação do processo de produção e montagem do protótipo; revisão e aperfeiçoamento do produto; montagem do protótipo aprimorado; ensaios laboratoriais (de acordo com as normas); avaliação dos resultados.

Observa-se que está em andamento o processo de anelamento das árvores que serão utilizadas na execução dos protótipos a serem testados, objetivando a redução no surgimento de frestas, devido às tensões de crescimento da espécie. Dessa forma, espera-se obter o aproveitamento máximo do material com perda mínima na forma de resíduos, contribuindo para a otimização do uso do material em relação aos procedimentos usuais de produção de casas de madeira.

Com base nas etapas e avaliações cumpridas até o momento, confirma-se a hipótese da pesquisa, que considera a possibilidade de desenvolver um sistema construtivo em tora de eucalipto, de fácil execução, que atenda aos critérios mínimos de desempenho e se adeque à população da região produtora da matéria-prima.

\section{STATUS DA SUBMISSÃO}

Recebido: 16/09/2011

Aceito: 20/02/2012

Resumo publicado online: 22/03/2012

Artigo completo publicado: 30/06/2012

\section{AUTOR(ES) PARA CORRESPONDÊNCIA}

\section{Emanuella Sossai Altoé}

Centro de Artes - Laboratório de Planejamento e Projetos - LPP, Universidade Federal do Espírito Santo - UFES, Av. Fernando Ferrari, 514, Cemuni I, Goiabeiras, CEP 29075-910,

Vitória, ES, Brasil

e-mail: manualtoe@hotmail.com

\section{REFERÊNCIAS}

Associação Brasileira de Normas Técnicas - ABNT. NBR 15575: desempenho para edificações habitacionais de até cinco pavimentos. Rio de Janeiro, 2010.

Associação Brasileira de Normas Técnicas - ABNT. NBR 7190: projeto de estruturas de madeira. Rio de Janeiro, 1997.
Associação Brasileira de Normas Técnicas - ABNT. NBR 8456: postes de eucalipto preservado para redes de distribuição de energia elétrica. Rio de Janeiro, 1984.

Associação Brasileira de Produtores de Florestas Plantadas - ABRAF. Anuário estatístico da ABRAF 2010 ano base 2009. Brasília: ABRAF; 2010.

Alzate SBA. Caracterização da madeira de árvores de clones de Eucalyptus grandis, E. saligna E E. grandis $x$ urophylla [tese]. Piracicaba: Centro Acadêmico de Engenharia Florestal, Universidade de São Paulo; 2004.

Calil Junior C, Brito LD. Manual de projeto $e$ construção de estruturas com peças roliças de madeira de reflorestamento. São Carlos: EESC/USP; 2010.

Dreyer LC, Hauschild M Z, Schierbeck J. A framework for social life cycle impact assessment, Lyngby/Holte. International Journal of Life Cycle Assessment - LCA 2006; 11: 88-97.

Elder AJ. Construccion. Madrid: Blume Ediciones; 1977.

Esteban M, Arriaga F, Íñiguez G, Bobadilla I, Mateo R. Influencia de las fendas en la resistencia de la madera estructural. Materiales de Construcción 2010; 60: 115132.

Foelkel CEB. Madeira de eucalipto: da floresta ao digestor. Piracicaba: Boletim Informativo IPEF; 1978.

Gérard J, Bailleres H, Fournier M, Thibaut B. Qualité du bois chez les eucalyptus de plantation - Etude de variation de trois propriétés de référence. Bois et Forêts des Tropiques 1995; 245: 101-111.

Gonçalves FG. Avaliação da qualidade da madeira de híbrido clonal de eucalyptus urophylla $x$ grandis para produtos sólidos [dissertação]. Vitória: Centro de Ciências Agrárias, Universidade Federal do Espírito Santo; 2006.

International Organization for Standardization - ISO. ISO 6241: performance standards in building: principles for their preparation and factors to be considered. Geneuve: ISO; 1984.

Junta del Acuerdo de Cartagena - JUNAC. Manual de disenõ para maderas del grupo andino. Lima: PADT/ REFORT/JUNAC; 1984

Mitidieri Filho CV. Avaliação de desempenho de componentes e elementos construtivos destinados a habitações: proposições específicas a avaliação de desempenho estrutural [tese]. São Paulo: Escola Politécnica, Universidade de São Paulo; 1998.

National Forest Products Association - NFPA. Design as wood frame structure for permanence. Washington: NFPA; 1980.

Rocha NMLL. Sistema construtivo "1/4 de log" [monografia]. Vitória: Centro de Artes, Universidade Federal do Espírito Santo; 1994. 
Sabbatini FH, Franco L. Notas de aula da disciplina de Tecnologia de produção de vedaçães verticais - TG $04 e$ PCC 2435 [online]. São Paulo; EPUSP, 2001. [cited 2001 nov. 20]. Available from: http://www.pcc.usp.br/ Graduação/PCC2435-aula18a.pdf

Santos MP, Aguilar MTP. Painéis de madeira como vedação vertical em construções [online]. Cadernos de Arquitetura e Urbanismo 2007; 14(15): 242-263. [cited 2010 set. 02]. Available from: http://www. pucminas.br/imagedb/documento/DOC_DSC_ NOME_ARQUI20081029100808.pdf.

Szücs CP. Autoconstrução em madeira [online]. UFSC; 1992. [cited 2007 jan. 15]. Available from: www. arq.ufsc.br/arq5661/madeiras/historia.html.

Universidad del Bio-Bio. Edificio en Madera. Concepción: Anibal Pino; 1998. 